\title{
Transdisciplinary Assistance and Translational Research Strategies to Improve the Quality of Life of Older Adults at Early Stages of Alzheimer Disease
}

\author{
Pablo Gr Sanz ${ }^{1,2}$, Lina Grasso ${ }^{1,2}$ and Francisco J Barrantes ${ }^{3,4 *}$ \\ ${ }^{1}$ Spanish Hospital, Argentina \\ ${ }^{2}$ Center for Research in Psychology and Psychopedagogy, Pontifical Catholic University of Buenos Aires, Argentina \\ ${ }^{3}$ National Scientific and Technical Research Council of Argentina (CONICET), Argentina \\ ${ }^{4}$ Faculty of Medical Sciences, Pontifical Catholic University of Buenos Aires, Argentina
}

Submission: May 08, 2018; Published: May 25, 2018

*Corresponding author: Francisco J Barrantes, Laboratory of Molec. Neurobiology, BIOMED, UCA-CONICET, Buenos Aires, Argentina,

Email: francisco_barrantes@uca.edu.ar

\begin{abstract}
Alzheimer disease (AD) is the most prevalent form of dementia. As the world population ages, the number of people suffering from dementia is increasing dramatically and yet we still ignore the pathophysiology of $\mathrm{AD}$ and lack effective therapeutic tools to deal with it. These two deficiencies, together with the search for early diagnostic tools, constitute the most obvious challenges in current biomedical research on $\mathrm{AD}$. In the meantime, healthcare efforts are being addressed at improving the quality of life of AD patients, their family and their caregivers. In this context, Translational Medicine, an interdisciplinary branch within the biomedical field, is called upon to play a key role in transferring the knowledge acquired in the laboratory to the bedside ("from bench to bedside"). Translational Medicine combines disciplines, resources, experience and techniques to promote improvements in prevention, diagnosis and therapies under the umbrella of a new conceptual and action framework going beyond mere knowledge sharing. Based on new translational research concepts, this short perspective on the subject describes the methodological background and conceptual framework of transdisciplinary assistance designed for patients diagnosed with Mild cognitive impairment (MCI). Psychoeducational strategies for improving the quality of life of the patients, relatives and caregivers are also discussed.
\end{abstract}

Keywords: Translational research; Transdisciplinary assistance; Alzheimer's disease; Mild cognitive impairment

\section{Introduction}

Aging is characterized by high inter individual variability related to inheritance and the cumulative effect of vital events and determinants of functional differences (cognitive, emotional and behavioral), all interdigitating with biological, social, cultural, biomedical and technological advances accomplished in the last half century. In addition to age as a conditioner of health status and degree of autonomy, there are pathological phenomena that depart from normal aging, leading to disability and dependence, and which are not necessarily associated with short-term mortality. By 2050, it is estimated that the world population above 60 years of age will amount to 2 billion people [1]. The number of people suffering from dementia is increasing as the world population ages; it is speculated that over 75 million people will have some form of dementia by 2030 [1]. Most of this growth will occur in developing countries, whose inhabitants are currently lagging behind those segments of the world population with growing life expectancy. Alzheimer disease (AD), the most frequent form of dementia, comprises between $60-70 \%$ of all cases. It is estimated that in the U.S.A. alone (currently with 5.7 million $\mathrm{AD}$ cases) the number of people over 65 with Alzheimer dementia will reach 7.1 million by 2025 , representing approximately $30 \%$ increase in a span of only 7 years [2]. Available evidence supports the view that symptomatologically silent pathophysiological processes precede the clinical debut of AD by approximately ten years; yet its early detection remains a challenge.

This brief perspective describes the methodological background and conceptual framework for the application of transdisciplinary assistance, based on new translational research concepts, to patients diagnosed with $\mathrm{MCI}$, and psychoeducational strategies addressing quality of life improvements for the patients, their relatives and caregivers. The «new lexicon» for 
clinical trials establishes the presence of preclinical stages in $\mathrm{AD}$, determined by the existence of pathophysiological activity associated with the morbid entity having a) insufficient clinical manifestations (symptomatology) to sustain the diagnosis of full AD-type dementia but b) sufficient to presume its occurrence due to the presence of symptomatic signs of lesser magnitude and/ or the positivity of biomarkers with a high degree of specificity $[3,4]$. However, the partial and sometimes limited evidence for their use and accessibility, makes the latter not applicable as presymptomatic diagnostic tools within the framework of common healthcare practice and especially of the elderly, an age group for which these biomarkers seem to be of limited informative value $[5,6]$. Instead, in daily clinical practice, when faced with an oligosymptomatic condition, one assumes to be in the presence of a "MCI suggestive of AD progression" [7,8].

Although early detection and effective treatment are undoubtedly the main aims of current research efforts, contributions from basic science can only be located at the base of the "evidence-based Medicine» pyramid, necessarily requiring confirmation by applied clinical research. There are still no animal models expressing all aspects of $\mathrm{AD}$ and the inferences derived from animal experimentation are seldom applicable to clinical practice. Within this context, Translational Medicine, an interdisciplinary branch of the biomedical field, is called upon to play a key role in attempting to apply the discoveries of the basic sciences for the benefit of the patients, transferring the knowledge acquired in the laboratory to the bedside ( from bench to bedside»). It combines disciplines, resources, experience and techniques to promote improvements in the prevention, diagnosis and therapies [9] as applied to the community [10]. These interventions represent a challenge for current science and require the effective and deliberate interaction of transdisciplinary knowledge.

\section{Therapeutic management proposals for AD}

Although we lack accurate evidence to support any intervention aimed at delaying or reducing the risk of $\mathrm{AD}$, there are epidemiological studies that suggest several prophylactic approaches, e.g. use of anti-inflammatory and cholesterolreducing drugs, regular physical exercise, Mediterranean diet [11] or even high fish intake [12]. The management of these variables in later stages of $\mathrm{AD}$ (once the symptomatic phase of the disease is apparent) is controversial, since the onset of amyloid deposit and consequent neuronal loss commences decades before the first symptoms of the disease appear. These concerns also apply to the educational achievements (or improvements in mental activity) suggested as protective factors, arguing a delay of symptomatic onset through a hypothetical increase in the density of brain synaptic connections and cognitive reserve factors $[13,14]$.

\section{Transdisciplinary approach}

The concept of a transdisciplinary approach involves interdisciplinarity, i.e. integrative cross-talk between several disciplines, arising from new needs [15] and multidisciplinarity, i.e. the sharing of a common objective. The combination of the two results in a new conceptual and action framework, the transdiscipline. This involves an entirely new approach requiring the construction of a framework which goes beyond the mere sharing of individual knowledge. In short, multi-, interand transdisciplinarity differ in the relationship shared by the disciplines involved. Multidisciplinarity involves cooperation that can be mutual and cumulative, but not interactive. Interdisciplinarity implies integration, the mixing of practices and assumptions. It is in the third level -transdiciplinarity- that a new framework emerges, fusing the dialogues [16]. The level of attention demanded in caring for the elderly is highly stressful, often leading to exhaustion, both in the case of the patient's direct relatives and of the caregivers. In this context, adaptation and psychological education are valuable tools that can diminish the burden - of family, caregivers and health professionals, thus improving the wellbeing and quality of life of the elderly. The need for care of these patients often exceeds the capacity of the family, leading to long-term hospitalizations. The combination of high prevalence and high cost of care needs, together with the economic crisis of health systems and the emerging high impact of informal care, are some of the factors to be taken into consideration in seeking to achieve adequate health policies.

\section{Adaptation and psychoeducation}

The impact of the transdisciplinary therapeutic management approach for $\mathrm{AD}$ is potentially much greater than any isolated medical or pharmacological intervention. The main goals of this approach are disability reduction, minimizing adverse drug effects, and maximizing the skills and knowledge of the caregiver. This approach promotes the social activity of the patient (in clubs for the third age, day centers, residential care homes and similar bodies), provides the caregiver with hygiene, dietary and behavioral management guidelines (such as sleep cycle, environmental management, hygiene-bathroom-feeding routines and other recommendations for daily habits) and reduces the need for pharmacological intervention for many difficult behaviors (such as obfuscation, restlessness, agitation, «sunset phenomenon» etc.). Educating and training caregivers in the characteristics of the disease, accident prevention and management of intercurrences helps reduce their perception of overload and lessens the likelihood of complications associated with a neurodegenerative disease (such as infections, or metabolic alterations, which can manifest themselves by e.g. abrupt behavioral changes). Financial planning, the willingness to advance medical directives (of management and care) and legal advice, as well as the experience of the AD patient's family, all improve patient autonomy. Participation in prevention programs is also of great value to caregivers, as it can convey a sense of hope and positive results, within the context of an illness. The impact of $\mathrm{AD}$ on the quality of life of the patient, the family and society calls for the coordination and integral management of health care efforts in order to avoid analysis of the problem on a purely economic base. 


\section{Methods for the diagnosis, prognosis and non- pharmacological treatment of patients with MCI}

Neuropsychological evaluation is a useful tool to differentiate between age-related mnesic decline and mnesic deficit, produced by the cognitive deterioration secondary to AD. The appropriate interpretation of these pathological alterations requires that they be approached from a transdisciplinary perspective, with the patient in his/her familiar context. Within this frame of reference, the design of non-pharmacological intervention and cognitive stimulation programs for older adults with MCI allows us to establish parameters for the study of neuroplasticity as a diagnostic-therapeutic method and its relationship with other possible prognostic factors and objective developmental measures of progression to dementia, based on a transdisciplinary and translational research approach. The World Action Plan on the Public Health Response to Dementia 2017-2025 [17] provides outlines for the follow-up of MCI patients under treatment and the care of the families under the transdisciplinary assistance and translational research approach outlined here.

\section{Acknowledgement}

Thanks are due to Prof. Dr. R. J Giannaula, Head of Neurology Division, Spanish Hospital for his permanent support and materials provided.

\section{References}

1. World Health Organization (2018) Aging and health.

2. Alzheimer's Association (2018) Alzheimer 's disease facts and figures. Alzheimer's \& Dement 14(3): 367-429.

3. Foster NL (2007) A new framework for the diagnosis of alzheimer's disease. Lancet Neurology 6(8): 667-669.

4. Mc Khann GM, Knopman DS, Chertkow H, Hyman BT, Jack CR, et al. (2011) The diagnosis of dementia due to alzheimer's disease: Recommendations from the national institute on aging-alzheimer's association workgroups on diagnostic guidelines for alzheimer's disease. Alzheimer's Dement 7(3): 263-269.

5. Lopez OL, Klunk WE, Mathis C, Coleman RL, Price J, et al. (2014) Amyloid, neurodegeneration and small vessel disease as predictors of dementia in the oldest-old. Neurology 83(20): 1804-1811.

6. Pierce AL, Bullain SS, Kawas CH (2017) Late-onset Alzheimer disease. Neurologic Clinics 35(2): 283-293.

7. Petersen RC, Smith GE, Waring SC, Ivnik RJ, Tangalos EG, et al. (1999) Mild cognitive impairment: clinical characterization and outcome. Archives of Neurology 56(3): 303-308.

8. Petersen RC, Morris JC (2005) Mild cognitive impairment as a clinical entity and treatment target. Archives of Neurology 62(7): 1160-1163.

9. Cohrs RJ, Martin T, Ghahramani P, Bidaut L, Higgins PJ (2014) Translational medicine definition by the european society for translational medicine. New Horizons in Translational Medicine 2(3): 86-88.

10. Woolf SH (2008) The meaning of translational research and why it matters. JAMA 299(2): 211-213.

11. Scarmeas N, Luchsinger JA, Schupf N, Brickman AM, Cosentino S, et al. (2009) Physical activity, diet and risk of alzheimer disease. JAMA 302(6): 627-637.

12. Morris MC, Brockman J, Schneider JA, Wang Y, Bennett DA, et al. (2016) Association of seafood consumption, brain mercury level, and APOE $\varepsilon 4$ status with brain neuropathology in older adults. JAMA 315(5): 489497.

13. Stern Y (2002) What is cognitive reserve? Theory and research application of the reserve concept. J Inter Neuropsy Soc 8(3): 448-460.

14. Stern Y, Habeck C, Moeller J, Scarmeas N, Anderson KE, et al. (2005) Brain networks associated with cognitive reserve in healthy young and old adults. Cerebral Cortex 15(4): 394-402.

15. Tamayo Y, Tamayo M (2004) Diccionario de la investigación científica ( $\left.2^{\text {nd }} e d n\right)$, Limusa, México, USA, p. 172.

16. Augsburg T (2005) An introduction to interdisciplinary ( $2^{\text {nd }}$ edn), Kendall Studies, Dubuque, USA, p. 56.

17. World Health Organization (2017) Development of a draft global action plan on the public health response to dementia. Comprehensive mental health action plan.

\section{Your next submission with Juniper Publishers} will reach you the below assets

- Quality Editorial service

- Swift Peer Review

- Reprints availability

- E-prints Service

- Manuscript Podcast for convenient understanding

- Global attainment for your research

- Manuscript accessibility in different formats

( Pdf, E-pub, Full Text, Audio)

- Unceasing customer service

Track the below URL for one-step submission https://juniperpublishers.com/online-submission.php 